\title{
Comparative transcriptome analysis reveals the regulatory networks of cytokinin in promoting the floral feminization in the oil plant Sapium sebiferum
}

Jun $\mathrm{Ni}^{1+}$, Faheem Afzal Shah ${ }^{2 \dagger}$, Wenbo Liu ${ }^{1 \dagger}$, Qiaojian Wang ${ }^{2}$, Dongdong Wang ${ }^{2}$, Weiwei Zhao ${ }^{1}$, Weili Lu', Shengwei Huang ${ }^{1}$, Songling $\mathrm{Fu}^{2}$ and Lifang $\mathrm{Wu}^{1 *}$

\begin{abstract}
Background: Sapium sebiferum, whose seeds contain high level of fatty acids, has been considered as one of the most important oil plants. However, the high male to female flower ratio limited the seed yield improvement and its industrial potentials. Thus, the study of the sex determination in S. sebiferum is of significant importance in increasing the seed yield.

Results: In this study, we demonstrated that in S. sebiferum, cytokinin (CK) had strong feminization effects on the floral development. Exogenous application with 6-benzylaminopurine (6-BA) or thidiazuron (TDZ) significantly induced the development of female flowers and increased the fruit number. Interestingly, the feminization effects of cytokinin were also detected on the androecious genotype of S. sebiferum which only produce male flowers. To further investigate the mechanism underlying the role of cytokinin in the flower development and sex differentiation, we performed the comparative transcriptome analysis of the floral buds of the androecious plants subjected to 6-BA. The results showed that there were separately 129, 352 and 642 genes differentially expressed at $6 \mathrm{~h}, 12 \mathrm{~h}$ and $24 \mathrm{~h}$ after 6-BA treatment. Functional analysis of the differentially expressed genes (DEGs) showed that many genes are related to the hormonal biosynthesis and signaling, nutrients translocation and cell cycle. Moreover, there were twenty one flowering-related genes identified to be differentially regulated by 6-BA treatment. Specifically, the gynoecium development-related genes SPATULA (SPT), KANADI 2 (KAN2), JAGGED (JAG) and Cytochrome P450 78A9 (CYP79A9) were significantly up-regulated, whereas the expression of PISTILLATA (PI), TATA Box Associated Factor II 59 (TAFII59) and MYB Domain Protein 108 (MYB108) that were important for male organ development was down-regulated in response to 6-BA treatment, demonstrating that cytokinin could directly target the floral organ identity genes to regulate the flower sex.

Conclusions: Our work demonstrated that cytokinin is a potential regulator in female flower development in S. sebiferum. The transcriptome analysis of the floral sex transition from androecious to monoecious in response to cytokinin treatment on the androecious $S$. sebiferum provided valuable information related to the mechanism of sex determination in the perennial woody plants.
\end{abstract}

Keywords: 6-BA, TDZ, Floral feminization, Bioenergy plant, Sapium sebiferum

\footnotetext{
* Correspondence: Ifwu@ipp.ac.cn

†Jun Ni, Faheem Afzal Shah and Wenbo Liu contributed equally to this work.

${ }^{1}$ Key laboratory of high magnetic field and lon beam physical biology, Hefei

Institutes of Physical Science, Chinese Academy of Sciences, Hefei, Anhui

230031, China

Full list of author information is available at the end of the article
}

(c) The Author(s). 2018 Open Access This article is distributed under the terms of the Creative Commons Attribution 4.0 International License (http://creativecommons.org/licenses/by/4.0/), which permits unrestricted use, distribution, and reproduction in any medium, provided you give appropriate credit to the original author(s) and the source, provide a link to the Creative Commons license, and indicate if changes were made. The Creative Commons Public Domain Dedication waiver (http://creativecommons.org/publicdomain/zero/1.0/) applies to the data made available in this article, unless otherwise stated. 


\section{Background}

Sapium sebiferum, a member of the Euphorbiaceae family, is one of the most important perennial oil plants. It has attracted great attention due to its high oil production, pharmaceutical values, high ornamental values as landscape plant and its viability to grow in the marginal land (Peng et al. 2008; Yang et al., 2007). S. sebiferum has been cultivated as a valuable oil plant for more than 14 centuries, due to the high oil content of the seed coat and seed kernel, which can be used for the manufacture of industrial products, such as lubricant, soap and candles [1]. Aside from being a source for industrial purposes, the oil extracted from the S. sebiferum is also considered as a kind of renewable oil resources, which can be further exploited for the production of diesel fuel and fatty acid alkyl esters [2,3]. Nevertheless, low female to male flower ratio significantly limited the seed yield improvement and the industrial potentials of S. sebiferum. Most of the $S$. sebiferum plants are monoecious with separate male and female flowers on the same inflorescence, while some are androecious plants that only produce male flowers. There are over one hundred male flowers arrange in the narrow raceme-like inflorescence, while only with few female flowers growing at the base of the inflorescence. Thus, the manipulation of the flower sex differentiation by using the biochemical and genetic strategies was of significant importance in improving the seed yield in S. sebiferum.

Phytohormones are essential factors involved in the regulation of vegetative and reproductive growth in the plant kingdom. Phytohormones, such as cytokinin (CK), auxin, gibberellin (GA) and ethylene (ETH), were demonstrated to be involved in the regulation of flowering and sex determination in many species [4]. Generally, cytokinin, auxin and ethylene were considered as positive regulators in gynoecium development, whereas GA (gibberellin) promoted the development of androecious organs [5-8]. In Jatropha curcas and Plukenetia volubilis, exogenous application with cytokinin can increase the female flower number $[9,10]$. Nevertheless, the mechanisms how cytokinin regulated the sex determination remains largely unknown. In this study, we demonstrated that CK was a key regulator in sex determination in the oil plant S. sebiferum. CK treatment on the floral bud significantly induced the floral feminization and promoted the fruiting. As the seed yield improvement of $S$. sebiferum was greatly limited by the low female to male flower ratio, thus our findings will be of significant importance in the cultivation of S. sebiferum. Further, the feminization effect was also detected on the androecious genotype of $S$. sebiferum. To further investigate how CK regulated the transition of the floral bud from androecious to monecious, RNA-seq analysis was carried out on the floral buds of the androecious S. sebiferum at
$6 \mathrm{~h}, 12 \mathrm{~h}$ and $24 \mathrm{~h}$ after 6-BA treatment. The present study not only provided an effective method in improving the seed yield during S. sebiferum cultivation, the transcriptome data also provided insights in understanding the mechanism of sex determination regulated by cytokinin in the woody plants.

\section{Methods \\ Plant materials and growth conditions}

In this experiment, three-year-old $S$. sebiferum trees, growing in the experimental field in Hefei Institutes of Physical Science (N 31 $49^{\prime}$, E117 $\left.13^{\prime}\right)$, Chinese Academy of Sciences, were used for the hormonal treatment. Trees were planted with $2.5 \mathrm{~m} \times 2.5 \mathrm{~m}$ spacing, and fertilized every year before bud sprouting.

\section{Phytohormone preparation and application}

To make stock solutions $(20 \mathrm{mM})$ of phytohormones, 6-BA, TDZ, trans-zeatin (tZ) or kinetin was dissolved in $0.2 \mathrm{M} \mathrm{NaOH}$ solution. The stock solutions were diluted with water to make different concentrations of working solutions containing $0.05 \%$ Tween-20 [11]. All working solutions for each treatment had the same solvent. The floral buds (one week after its formation) were treated with working solutions using a $100 \mathrm{ml}$ plastic sprayer.

\section{Sample collection and RNA isolation for transcriptome sequencing and quantitative real time PCR}

Floral buds of the androecious plants (Additional file 1: Figure S1) were treated with 6-BA $(200 \mu \mathrm{M})$ and mock solution (containing the same solvent with 6-BA solution). The floral buds after removing the leaves (approximately $3 \mathrm{~mm}$ in length, Additional file 1: Figure S1) were collected at $6 \mathrm{~h}, 12 \mathrm{~h}$ and $24 \mathrm{~h}$ separately, and then immediately frozen in liquid nitrogen. Each treatment at each time point was prepared with six independent biological replicates (three for RNA seq, and three for quantitative real time PCR). The total RNA was extracted by using a Plant Total RNA Isolation Kit (Omega, China). RNA purity was checked by gel electrophoresis and NanoDrop 2000c spectrophotometer (Thermo Fisher, MA, USA). RNA concentration and integrity were separately determined using a Qubit 2.0 Flurometer (Life Technologies, Carlsbad, CA, USA) and Agilent Bioanalyzer 2100 system (Agilent Technologies, Santa Clara, CA, USA).

\section{Transcriptome sequencing and de novo transcriptome assembly}

Sequencing libraries (each sample with three biological replicates) were prepared following the instructions of the NEBNext Ultra RNA Library Prep Kit for Illumina (NEB, USA). The literary quality was determined using the Agilent Bioanalyzer 2100 system. The clustering of 
the index-coded samples was performed according to the instructions of cBot Cluster Generation System. Then the libraries were sequenced on the Illumina HiSeq 2000 platform at the Beijing Genomics Institute (BGI, Shenzhen, China) and the raw reads were generated in 90-bp paired-end format. The low-quality reads ( $<20$ Phred scores) were removed by Fastq_clean [12] and further assessed by FastQC [13]. The clean reads were assembled by using Trinity (version 2.0.6) [14]. The paired-end reads were then mapped to the de novo assemblies by using Bowtie (version 1.1.1) [15]. The abundance estimation was performed using Corset (version 1.03) [16].

\section{Transcript annotation and gene expression analysis}

All the assembled transcripts were searched against the NCBI non-redundant protein database $(\mathrm{Nr})$, Swiss-Prot protein database and NCBI non-redundant nucleotide sequence $(\mathrm{Nt})$ database. The GO functional classification was then carried out using Blast2GO program based on the $\mathrm{Nr}$ annotation [17]. The GO analysis was carried out by using the WEGO software [18]. The transcripts were aligned to the Clusters of Orthologous Groups of proteins (COG) database and Kyoto Encyclopedia of Genes and Genomes (KEGG) database [19, 20]. To quantify the differentially expressed unigenes, the read counts were calculated by using the fragments per kilobase of transcript per million fragments mapped method (FPKM) [21].

\section{Quantitative real time PCR (qPCR) analysis}

cDNA was synthesized according to the instructions of EasyScript One-Step gDNA removal and cDNA synthesis SuperMix (Transgen Biotechnology, Beijing, China). qPCR was performed using TaKaRa SYBR Premix Ex Taq $^{\text {Ta }}$ II (TaKaRa Biotechnology, Dalian, China) on the Roche Light Cycler 96 System (Roche, Swiss). The PCR procedures were as follows: $95^{\circ} \mathrm{C}$ for $5 \mathrm{~min}$; 45 cycles of $95{ }^{\circ} \mathrm{C}$ for $10 \mathrm{~s}, 60{ }^{\circ} \mathrm{C}$ for $10 \mathrm{~s}$, and $72{ }^{\circ} \mathrm{C}$ for $15 \mathrm{~s}$; the melting curve analysis was from $65{ }^{\circ} \mathrm{C}$ to $95{ }^{\circ} \mathrm{C}$. The information of the primers was listed as Additional file 2: Table S1.

\section{Statistical analyses}

Data were analyzed using the Statistical Product and Service Solution (SPSS) version 13.0 software. The significance between the hormone treated and control group was determined using Student's test.

\section{Results}

6-BA and TDZ had strong feminization effects on the floral development and promoted fruiting in S. sebiferum Based on the floral structure, S. sebiferum can be mainly divided into two main genotypes, S. sebiferum var. conferticarpa and S. sebiferum var. laxiarpa [22]. Most of S. sebiferum var. conferticarpa plants are monoecious, with few female flowers growing at the floral base, while some are androecious plants that only produce male flowers (Additional file 1: Figure S1). The results showed that exogenous 6-BA or TDZ treatment significantly induced the female flowers, which appeared at the position where the male flowers located (Fig. 1). The feminization effect was increased with increasing concentrations of 6-BA (Fig. 1a, b), or TDZ (Fig. 1c, d), reaching an average of 57.7 and 78.5 female flowers per inflorescence, separately by $6-\mathrm{BA}$ and TDZ treatment. TDZ treatment had better effects in promoting the floral development, resulting in larger floral size and higher female flower number than that by 6-BA treatment (Fig. 1). However, over-dosed 6-BA or TDZ (e.g. $1 \mathrm{mM}$ ) was actually toxic to the floral bud (Fig. 1e). Approximately $20-30 \%$ of the 6-BA- or TDZ-induced female flowers could further develop into fruits (Fig. 2). It was worthy to mention here that although trans-zeatin ( $\mathrm{tZ}$ ) or kinetin were two other types of cytokinins. Exogenous application with these $\mathrm{tZ}$ or kinetin had no effects on the flower development or fruiting in S. sebiferum (Figs. 1f and 2d, e).

\section{6-BA or TDZ treatment feminized the androecious genotype of $S$. sebiferum}

In $S$. sebiferum, there are a small population of androecious plants that only produces male flowers and bares no fruits (Additional file 3: Figure S2). The effects of cytokinin on the floral development on the androecious genotype of $S$. sebiferum was also investigated in this study. The results showed that 6-BA or TDZ treatment can induce the female flower development on the male inflorescence of the androecious S. sebiferum (Fig. 3a, b). The induced female flowers, which had similar structures with that of the normal flowers (Fig. 3c), were located at the position of the male flowers all over the whole inflorescence, and can further develop into fruits (Fig. 3d).

\section{Transcriptome sequencing of the floral buds of the} androecious $S$. sebiferum in response to 6-BA treatment The androecious genotype provided great advantages in investigating the mechanism of sex differentiation regulated by cytokinin in S. sebiferum. After 6-BA or TDZ treatment, abundant female flowers were induced in the "male inflorescence", thus we presumed that cytokinin was not only the key factor in regulating the sex differentiation in S. sebiferum, but also possibly participated in the formation of the androecious plants. The transcriptome analysis of the floral buds at the early developing stages of the androecious plants would be helpful for identification of key genes involved in the female flower 
a

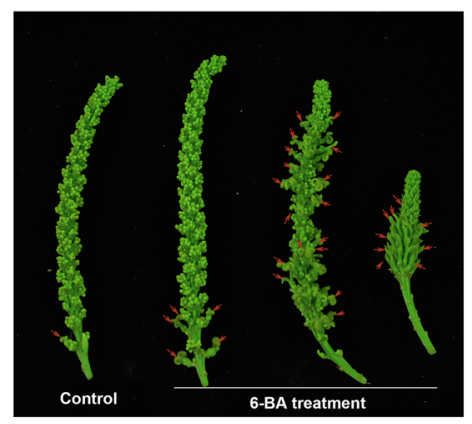

C

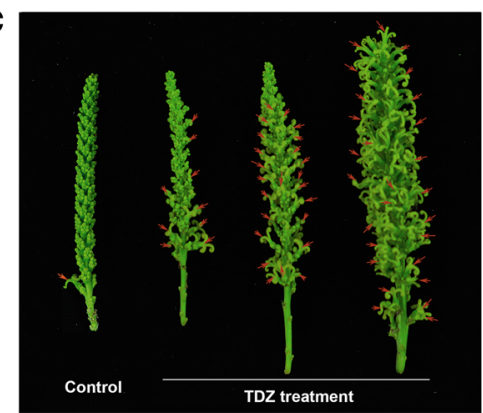

e

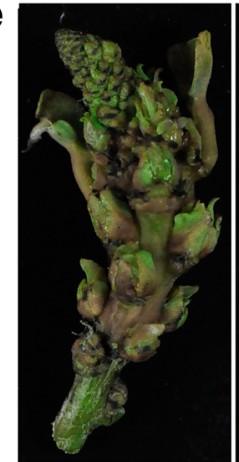

6-BA

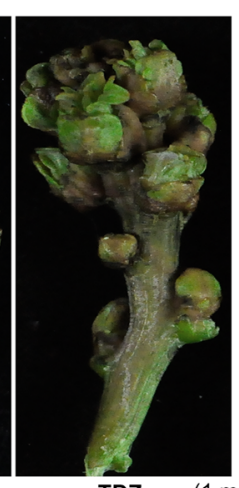

TDZ (1 mM)
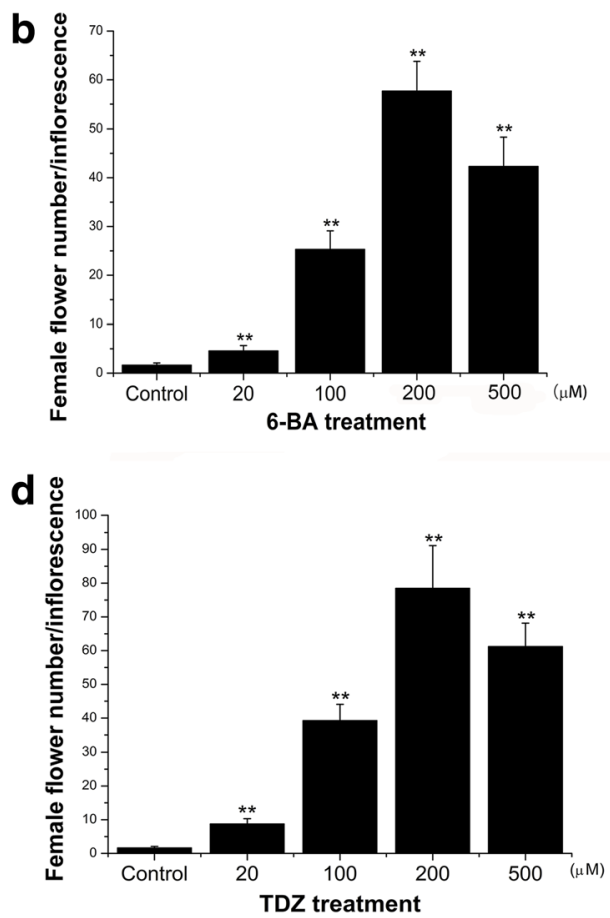

f

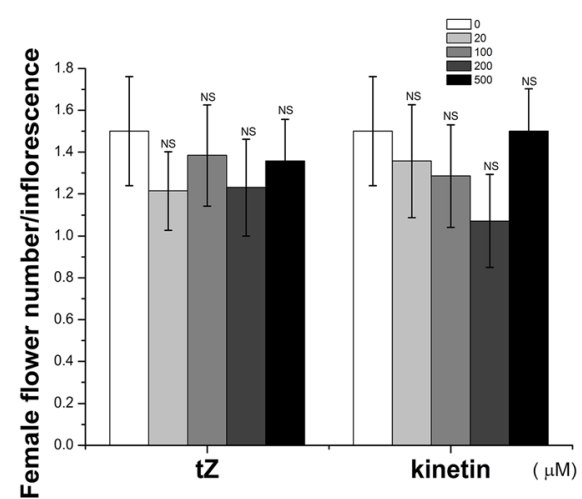

Fig. 1 Effects of 6-BA and TDZ on the induction of female flowers in S. sebiferum. a Inflorescences of control and 6-BA-treated groups. $\mathbf{b}$ Number of female flowers per inflorescence three weeks after 6 -BA treatment $(n=30)$. $\mathbf{c}$ Inflorescences of control and TDZ-treated groups. $\mathbf{d}$ Number of female flowers per inflorescence by TDZ treatment $(n=30)$. e Inflorescences of 1 mM 6-BA or TDZ treated groups. $\mathbf{f}$ Number of female flowers per inflorescence by $t Z$ and kinetin treatment $(n=30)$. Values are mean \pm SE. Significance between treatment and control was determined by Student's t test. Significance level: ${ }^{* *} P<0.01$. NS, no significance. Red arrows indicated the induced female flowers

formation and development in response to cytokinin in S. sebiferum.

In S. sebiferum, the floral buds were located at the terminal of each branchlet. One week after the floral bud formation (approximately $3 \mathrm{~mm}$ in length, Additional file 1: Figure S1), 6-BA $(200 \mu \mathrm{M})$ and mock solutions were directly applied to the floral buds. In total of six groups of samples (6-BA- and mock-treated floral buds at $6 \mathrm{~h}, 12 \mathrm{~h}$ and $24 \mathrm{~h}$, each group contains six biological replications) were collected for the following transcriptome sequencing and quantitative real-time PCR, aiming at identification of the early responsive genes that were involved in the sex determination regulated by cytokinin. Eighteen cDNA libraries were constructed and sequenced on the Illumina high-throughput sequencing platform. The detailed information of the transcriptome assembly can be found in Table 1 and Additional file 4: Tables S2-S4. The differences of gene expression levels were plotted with colored dots and there were separately 129, 352 and 642 genes differentially expressed at $6 \mathrm{~h}$, $12 \mathrm{~h}$ and $24 \mathrm{~h}$ after 6-BA treatment (Fig. 4, Additional file 5: Tables S5-S7). To validate the accuracy of the transcriptome sequencing results, the expression level of fourteen differentially expressed genes (DEGs) was 


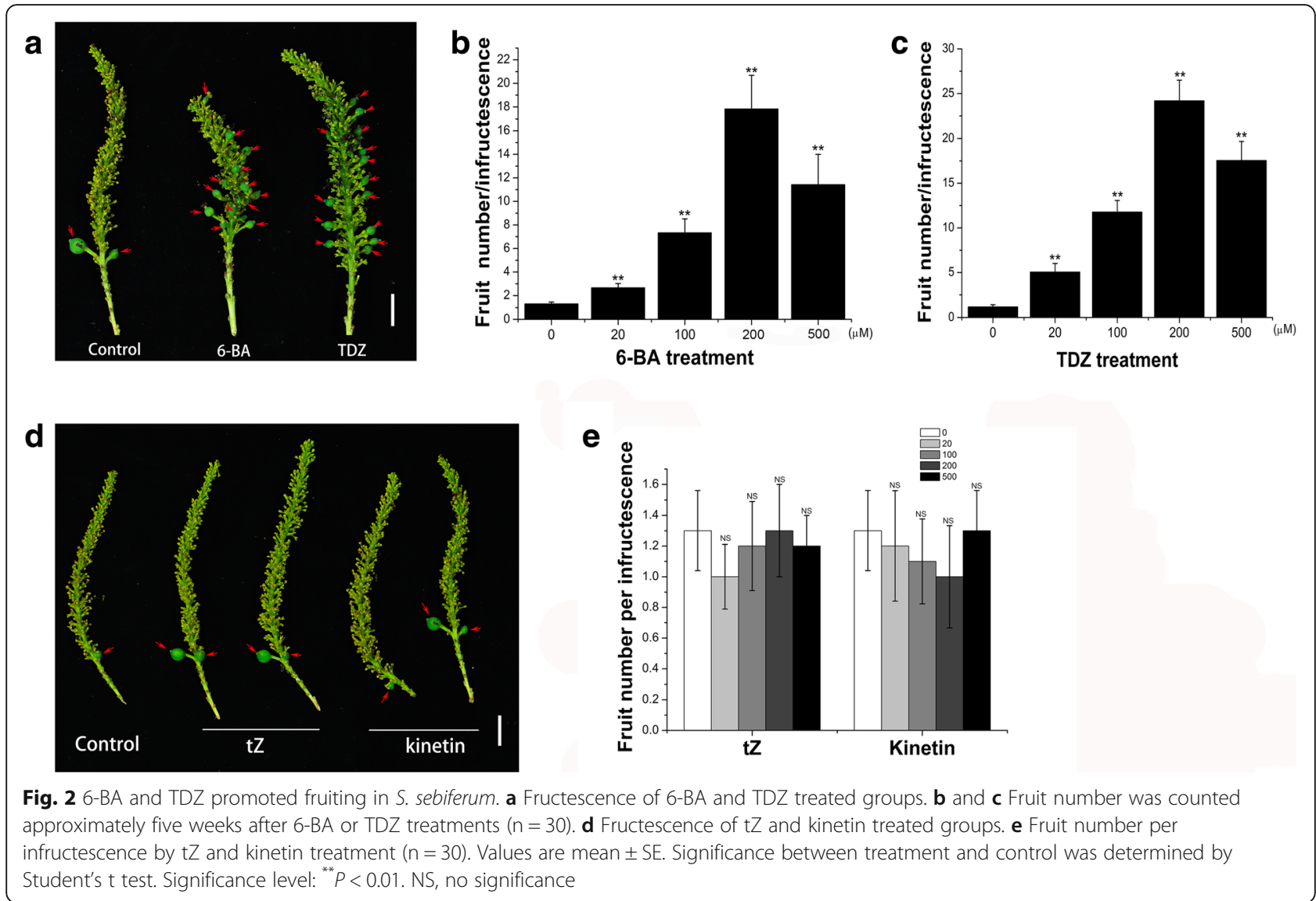

determined by quantitative real-time PCR (qPCR). The expression profiles of these genes by qPCR were consistent with the values derived from the RNA-seq (Table 2). Kyoto Encyclopedia of Genes and Genomes (KEGG) and Gene Ontology (GO) analysis were further carried out to generally describe the biological functions of these differentially expressed genes (DEGs) (Fig. 5 and Additional file 3: Figure S2). The results showed that the DEGs were mainly classified into 19 categories by KEGG analysis and the predominant categories were mostly related to "Metabolism" (58\%) and "Genetic information processing" (21\%) (Fig. 5). Further, the predominant categories by GO analysis were "metabolic process", "cellular process", "cell", and "catalytic activity" (Additional file 6: Figure S3), which was closed correlated to the basic biological functions of cytokinin in promoting cell growth, replication and metabolism.

\section{Differentially expressed genes related to cell cycle and nutrient translocation}

The KEGG analysis revealed that abundant DEGs were classified into "Metabolism" and "Genetic information processing" categories (Fig. 5). Many cell cycle related DEGs, including four cyclin genes, CYCD3 (CL6841.Contig3_All), CYCD6 (CL3342.Contig16_All and CL3342.Contig6_All), CYCH1 (CL384.Contig6_All), and some other DEGs, such as E2F Transcription factor 3 (E2F3, CL1239.Contig4_All), ANAC068 (CL12342.Contig2_All), Block of Cell Proliferation 1 (BOP1, Unigene9027_All), NEDD1 (CL659.Contig13_All) and Origin of Replication Complex $1 B$ (ORC1B, CL2740.Contig8_All) which encodes key transcription factors that involved in the regulation of cell division, were up-regulated after 6-BA treatment (Fig. 6a). Several DEGs that encoded DNA and RNA polymerases (Unigene7546_All, CL14256.Contig6_All, CL14312.Contig3_All and CL8049.Contig5_All) were also up-regulated in response to 6-BA treatment (Fig. 6a). In accompany with the enhanced cell division, the nutrients homeostasis in the floral bud was also affected by 6-BA treatment. The expression level of the nutrient translocation-related genes including Early Response to Dehydration 6 (ERD6, CL1189.Contig43_All), Glucose-6-Phosphate Translocator 2 (GPT2, CL17101.Contig1_All), Nucleotide/Sugar Transporter (NST, CL17241.Contig33_All) and UDP-Galactose Transporter 7 (UTR7, CL648.Contig66_All) that involved in sugar transportation, Oligopeptide Transporter 4 (OPT4, Unigene14375_All) in oligopeptide transportation, Cationic Amino Acid Transporter 7 (CAT7, Unigene35653_All) in amino acid transportation, 
a
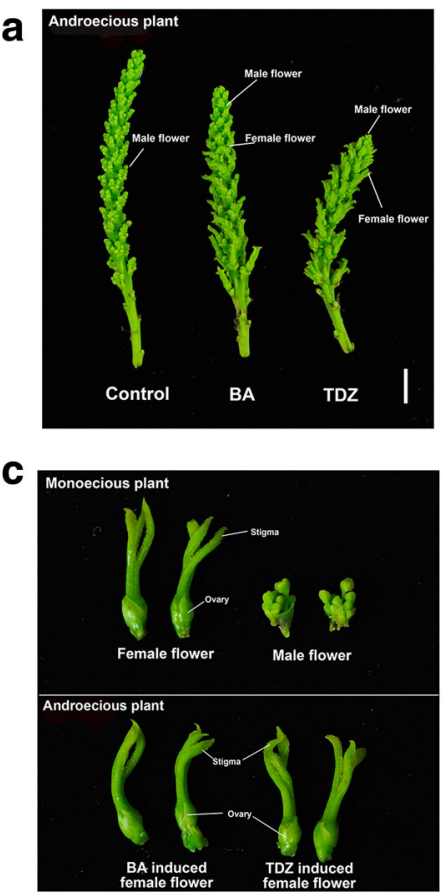

b
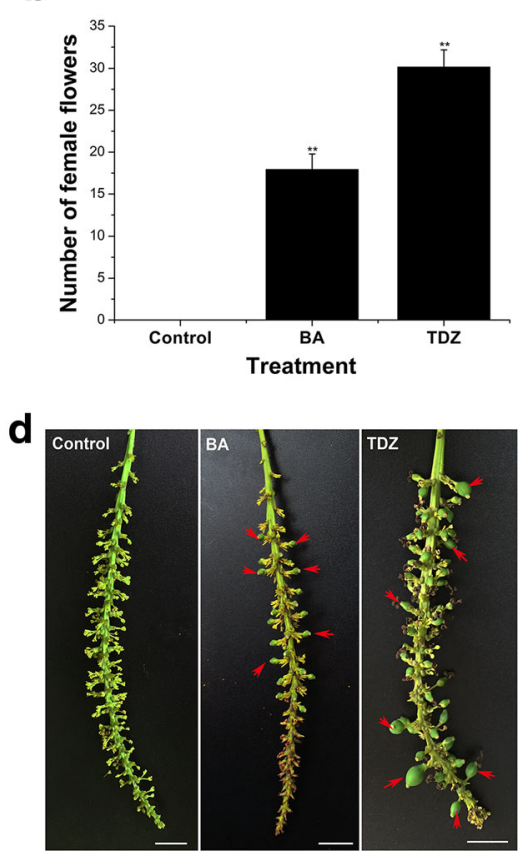

Fig. 3 6-BA or TDZ induced female flower development on the androecious S. sebiferum. a Inflorescences of control, 6-BA- and TDZ-treated S. sebiferum. $\mathbf{b}$ Number of female flowers was counted after 6-BA or TDZ treatment $(100 \mu \mathrm{M})(n=30)$. c 6-BA- or TDZ-induced female flowers on the androecious plants showed similar phenotype with that of the monoecious S. sebiferum. $\mathbf{d}$ Infructescences of the androecious plants after control, 6-BA- or TDZ treatment. Values are mean \pm SE. Significance between treatment and control was determined by Student's t test. Significance level: ${ }^{* *} P<0.01$. Bars $=1 \mathrm{~cm}$

Table 1 Summary of the transcriptome assembly

\begin{tabular}{|c|c|c|c|c|c|c|}
\hline Sample & Total Number & Total Length (nt) & Mean Length (nt) & N50 & N70 & $\mathrm{GC}(\%)$ \\
\hline $6 C-1$ & 78,134 & $72,513,692$ & 928 & 1585 & 988 & 40.19 \\
\hline $6 C-2$ & 83,602 & $82,610,570$ & 988 & 1709 & 1073 & 39.76 \\
\hline $6 C-3$ & 75,035 & $71,403,325$ & 951 & 1645 & 1026 & 40.05 \\
\hline $6 \mathrm{BA}-1$ & 71,419 & $68,445,465$ & 958 & 1648 & 1039 & 40.33 \\
\hline $6 \mathrm{BA}-2$ & 85,666 & $84,464,445$ & 985 & 1709 & 1076 & 39.71 \\
\hline $6 \mathrm{BA}-3$ & 81,033 & $77,824,709$ & 960 & 1662 & 1041 & 39.85 \\
\hline $12 C-1$ & 80,069 & $77,792,164$ & 971 & 1684 & 1062 & 39.91 \\
\hline $12 C-2$ & 79,399 & $77,063,614$ & 970 & 1670 & 1061 & 40.01 \\
\hline $12 C-3$ & 77,903 & $74,154,878$ & 951 & 1655 & 1036 & 40.03 \\
\hline $12 \mathrm{BA}-1$ & 77,472 & $74,784,107$ & 965 & 1671 & 1050 & 40.09 \\
\hline $12 \mathrm{BA}-2$ & 78,727 & $75,826,676$ & 963 & 1672 & 1051 & 40 \\
\hline $12 \mathrm{BA}-3$ & 77,233 & $74,834,430$ & 968 & 1686 & 1058 & 40.01 \\
\hline $24 C-1$ & 84,217 & $79,418,426$ & 943 & 1608 & 1004 & 39.99 \\
\hline $24 C-2$ & 69,973 & $64,954,222$ & 928 & 1605 & 1001 & 40.26 \\
\hline $24 C-3$ & 79,644 & $75,334,917$ & 945 & 1637 & 1022 & 39.93 \\
\hline $24 B A-1$ & 76,570 & $72,387,799$ & 945 & 1645 & 1021 & 40.04 \\
\hline $24 B A-2$ & 75,078 & $70,913,371$ & 944 & 1635 & 1021 & 40.14 \\
\hline $24 \mathrm{BA}-3$ & 74,125 & $69,581,278$ & 938 & 1629 & 1010 & 40.21 \\
\hline
\end{tabular}



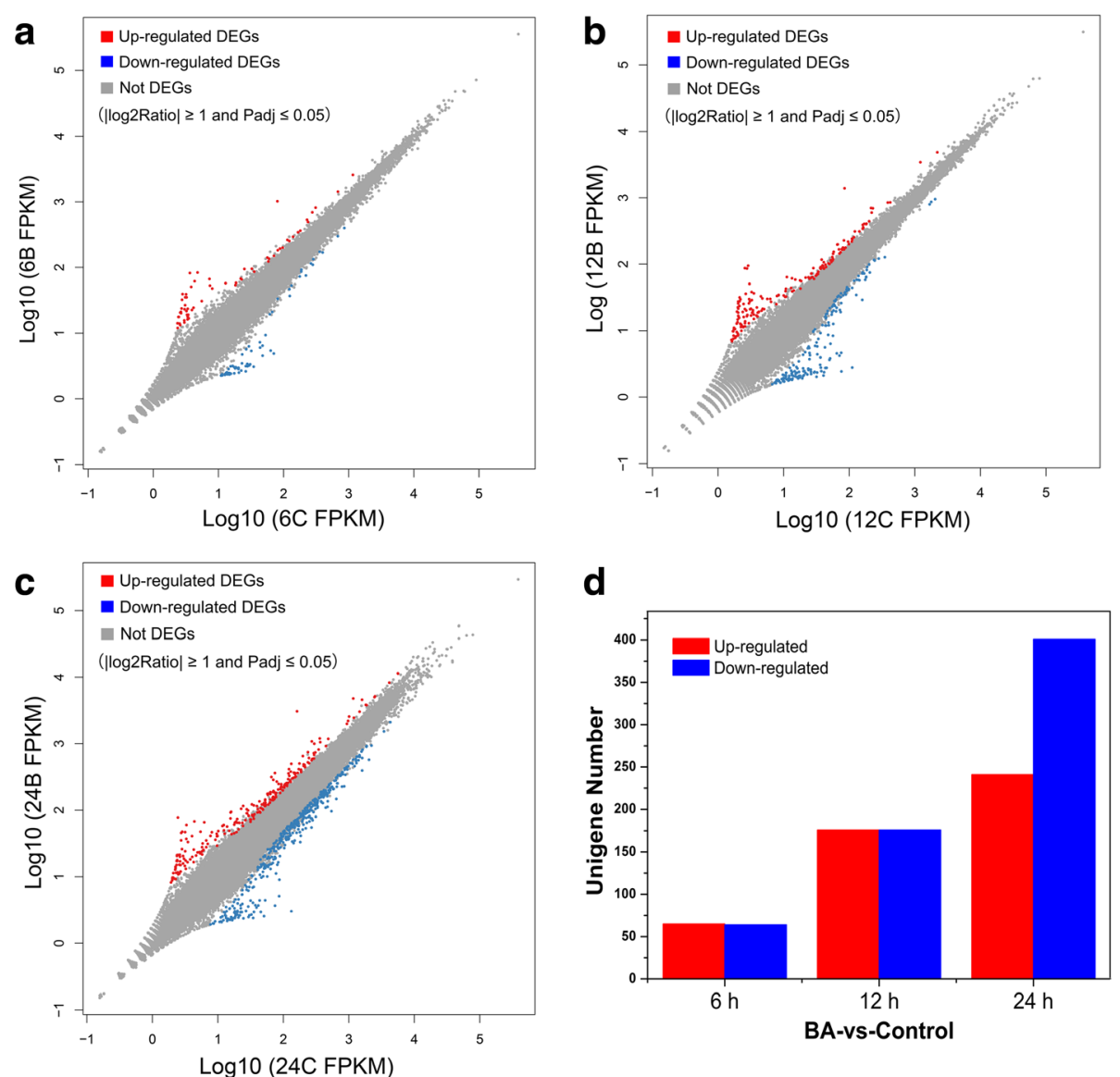

Fig. 4 Differentially expressed genes at $6 \mathrm{~h}, 12 \mathrm{~h}$ and $24 \mathrm{~h}$ after 6-BA treatment on the floral buds of the androecious $\mathrm{S}$. sebiferum. a-c. The differential gene expression was plotted using the FPKM method. The DEGs with $\mid \log 2$ ratio| $\geq 1$ and Padj $\leq 0.05$ were shown in red and green dots. $\mathbf{d}$ Number of DEGs. Red and green columns represented the number of up-, or down-regulated DEGs, respectively

Table 2 Log2-fold change (6-BA vs Control at 6, 12 and 24 h) of the DEGs between RNA-seq and qPCR

\begin{tabular}{|c|c|c|c|c|c|c|c|}
\hline \multicolumn{2}{|l|}{ Description } & \multicolumn{2}{|l|}{$6 \mathrm{~h}$} & \multicolumn{2}{|l|}{$12 \mathrm{~h}$} & \multicolumn{2}{|l|}{$24 \mathrm{~h}$} \\
\hline Gene ID & Gene Name & RNA-seq & $\overline{q P C R}$ & RNA-seq & $\overline{q P C R}$ & RNA-seq & $\overline{q P C R}$ \\
\hline CL3798.Contig10_All & Shaker Pollen Inward K+ Channel & 0.2 & -0.4 & 2.1 & 1.7 & 0.1 & 0.6 \\
\hline CL15451.Contig2_All & Cytochrome P450 78A9 & 0.6 & 0.3 & 1.1 & 1.6 & 1.1 & 0.9 \\
\hline CL14312.Contig3_All & RPB15.9.9 & 1.4 & 1.9 & 3.5 & 2.6 & 0.1 & -0.4 \\
\hline CL10984.Contig2_All & YUCCA4 & 1.1 & 1.6 & 0.8 & 1.5 & 1.2 & 2.5 \\
\hline CL8402.Contig2_All & Fantastic Four 3-like & 1.9 & 2.5 & 1.2 & 0.8 & 2.3 & 1.6 \\
\hline CL1856.Contig26_All & ATP-dependent DNA helicase & 3.8 & 3.2 & 0.5 & -0.3 & 0 & 0.5 \\
\hline CL1323.Contig24_All & Polygalacturonase & 2.9 & 2.5 & -1.3 & -1.6 & 0.7 & 0.2 \\
\hline CL14183.Contig4_All & FANCL isoform $\times 2$ & 0.3 & 0.1 & -3.9 & -2.6 & 0.2 & -0.5 \\
\hline CL4361.Contig13_All & Casein kinase I & -0.2 & 0 & -1.6 & -2 & 0.6 & 0.2 \\
\hline CL4670.Contig3_All & Ethylene Response DNA Binding Factor 4 & -1.1 & -2.2 & -0.5 & -0.1 & -2 & -1.3 \\
\hline CL8816.Contig1_All & uncharacterized protein & -0.2 & 0.5 & -0.15 & 0 & 3.9 & 2.8 \\
\hline CL2483.Contig2_All & $\beta$-1,3-galactosyltransferase 2 & 0.2 & -0.4 & 0.4 & -0.1 & -3 & -3.3 \\
\hline CL7852.Contig4_All & Response Regulator 5 & 1.2 & 2.4 & 0.9 & 1.5 & 1.4 & 2.6 \\
\hline CL14906.Contig2_All & Xyloglucan Endotransglycosylase & -1.2 & -2.3 & -1.1 & -0.4 & -1.4 & -1 \\
\hline
\end{tabular}




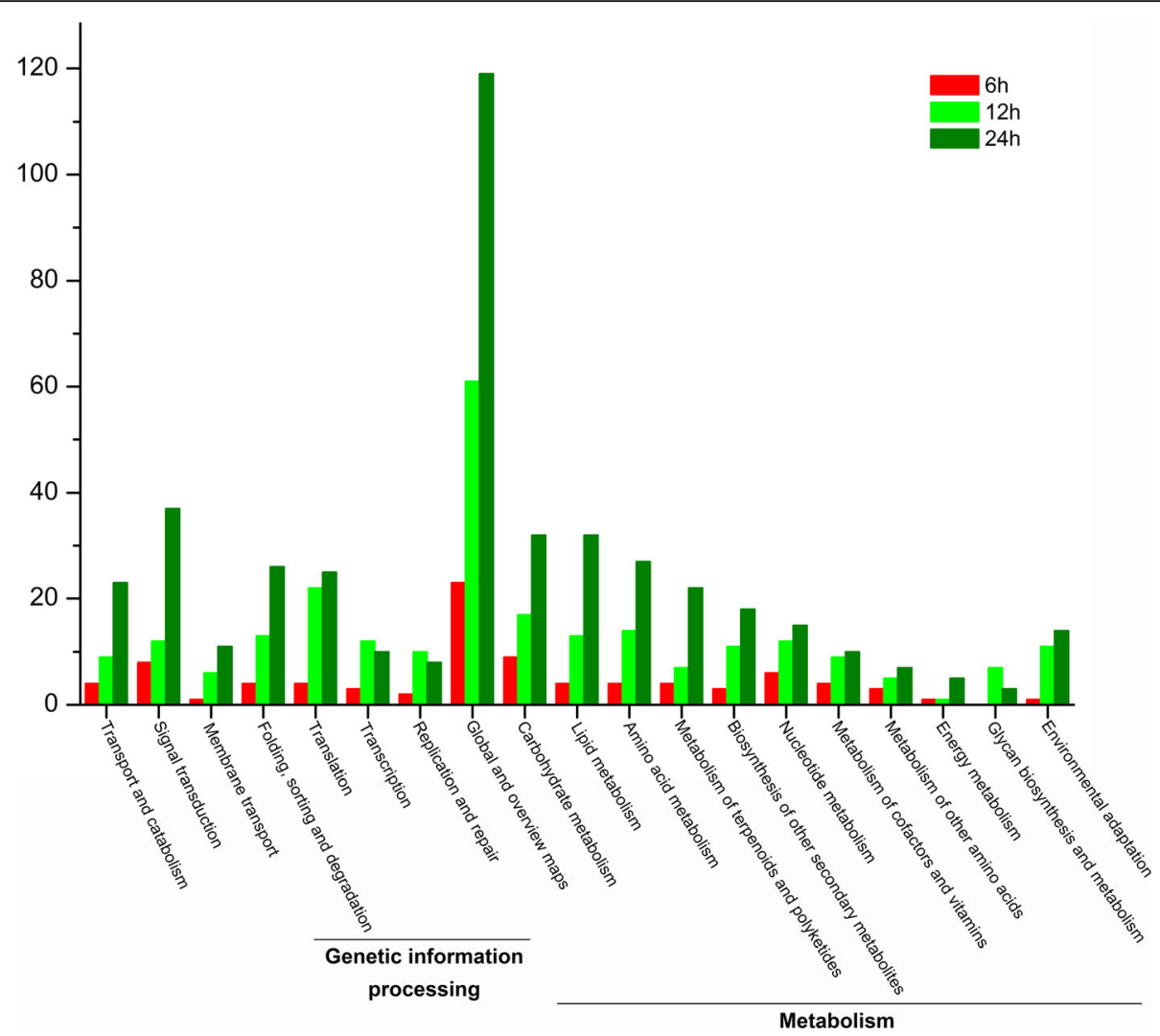

Fig. 5 KEGG analysis of the differentially expressed genes at $6 \mathrm{~h}, 12 \mathrm{~h}$ and $24 \mathrm{~h}$ after 6-BA treatment
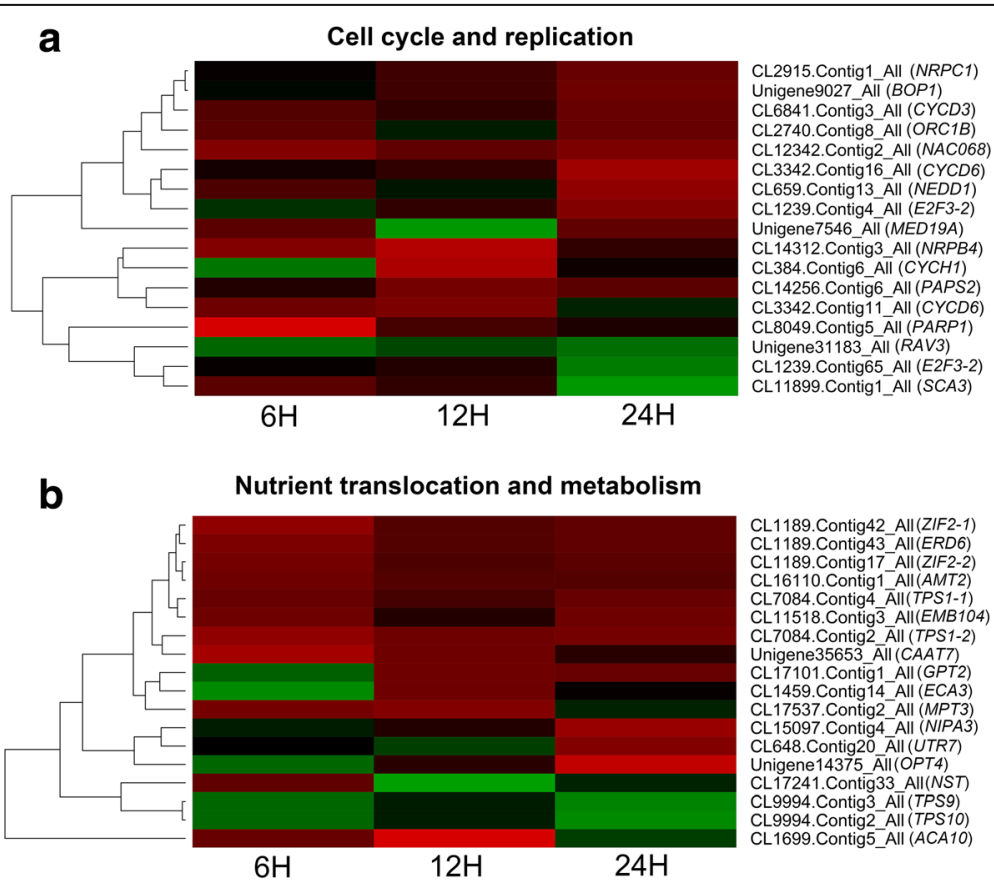

Fig. 6 Hierarchical clustering of the differentially expressed genes related to cell cycle and nutrient translocation after 6-BA treatment. The expression profiles of the differentially expressed genes related to cell cycle and replication (a), and the translocation of sugar, oligopeptide, magnesium, ammonium, nucleotide, phosphate, calcium and zinc (b) were obtained at 6 h, 12 h and $24 \mathrm{~h}$ after 6-BA treatment 
ENOR3L5 (CL15097.Contig4_All) in magnesium transportation, Ammonium Transporter 2 (AMT2, CL16110.Contig3_All) in ammonium transportation, Embryo Defective 104 (EMB104, CL11518.Contig3_All) in nucleotide transportation, Mitochondrial Phosphate Transporter 3 (MPT3, CL17537.Contig2_All) in phosphate transportation, two Calcium Transporting ATPases ACA10 (CL1699.Contig5_All) and ECA3 (CL1459.Contig14_All) in calcium transportation, and Zinc-Induced Facilitator 2 (ZIF2, CL1189.Contiga42_All and CL1189.Contig17_All) in zinc transportation, were mostly up-regulated in response to 6-BA treatment (Fig. 6b). Recent studies demonstrated that trehalose-6-phosphate (T6P) was directly involved in the regulation of flowering, the biosynthesis of which was tightly regulated by the Thehalose-6-Phosphate Synthase (TPS) [23]. The transcriptome data also showed that four TPS genes, TPS1 (CL7084.Contig2_All and CL7084.Contig4_All), TPS9 (CL9994.Contig3_All) and TPS10 (CL9994.Contig2_All), were differentially regulated by 6-BA treatment (Fig. 6b).

\section{Differentially expressed genes related to cytokinin metabolism and signaling}

After gene annotation, many cytokinin metabolism- and signaling-related genes were identified to be differentially expressed in response to 6-BA treatment (Fig. 7). Adenine Phophoribosyltransferases (APTs) and Cytokinin Oxidases $(C K X \mathrm{~s})$ are two key regulators in maintaining the endogenous cytokinin homeostasis. APTs participated in the interconversion of cytokinin bases into nucleotides, while CKXs can directly catalyze the degradation of cytokinins $[24,25]$. In this study, three APT genes ATP1 (CL5503.Contig22_All), APT5 (CL5503.Contig21_All and Cl5503.Contig27_All), and four CKX genes CKX3 (CL13408.Contig1_All), CKX5 (CL13173.Contig2_All and CL13173.Contig1_All), CKX7 (CL12919.Contig2_All), were significantly up-regulated at $6 \mathrm{~h}, 12 \mathrm{~h}$ and $24 \mathrm{~h}$ after 6-BA treatment (Fig. 7), suggesting a strong feedback regulation of $\mathrm{CK}$ homeostasis after 6-BA treatment.

Previous studies suggested that cytokinin signal transduction occurs though a two-component phosphorelay system. Arabidopsis response regulators (ARRs) can be classified into two groups (type A and type B), both of which are important components in cytokinin signal transduction [26]. Our results showed that the expression of four type A ARR genes, ARR3 (CL7852.Contig3_All), ARR4 (CL7852.Contig4_All), ARR5 (CL1788.Contig4_All) and ARR9 (Unigene12447), was up-regulated at $6 \mathrm{~h}, 12 \mathrm{~h}$ or $24 \mathrm{~h}$ after 6-BA treatment (Fig. 7). As the expression of type B ARRs was not significantly affected after 6-BA treatment, it suggested that in S. sebiferum, cytokinin signal transduction in the floral bud might be dependent on the regulation of type A ARRs.

\section{Differentially expressed genes related to hormonal} biosynthesis, metabolism and signaling

Phytohormones, such as CK, auxin, ABA, ETH and GA are the key regulators in controlling floral initiation, development, and sex differentiation. We further investigated whether the biosynthesis and signaling of the other hormones were affected by 6 -BA treatment. The results showed that three auxin metabolism- and six auxin signaling-related genes were differentially expressed at $6 \mathrm{~h}, 12 \mathrm{~h}$ or $24 \mathrm{~h}$ after 6 -BA treatment (Fig. 7). YUCCA2 (YUC2) and YUCCA2 (YUC4) which encoded two YUC flavin monooxygenases, played essential roles in auxin biosynthesis [27]. In $S$. sebiferum, both YUC2 (CL10701.Contig1_All) and YUC4 (CL10984.Contig2_All) was up-regulated at $12 \mathrm{~h}$ and reached a higher expression level at $24 \mathrm{~h}$ after 6-BA treatment (Fig. 7). Meanwhile, the expression of Dioxygenase for Auxin Oxidation 1 (DAO1, CL2608.Contig20_All), which encoded a key auxin oxidase and was also a major contributor to IAA degradation [28], was firstly decreased at $12 \mathrm{~h}$, then increased at $24 \mathrm{~h}$ after 6 -BA treatment (Fig. 7), suggesting there could be a transient increase of endogenous auxin level after 6-BA treatment. Further, three ABA biosynthesis- and five ABA signaling-related genes were also regulated by 6-BA treatment. The expression of ABA biosynthesis-related genes XERICO (Unigene42548_All and CL8997.Contig4_All) and NCED3 (CL9818.Contig6_All) was significantly down-regulated by 6-BA treatment (Fig. 7). Four ABA signaling-related genes Regulatory Components of ABA Receptor 10 (RCAR10, Unigene31612_All), Ring Domain Ligase 2 (RGLG2, CL5656.Contig10_All), Growth-regulating Factor 3 (GRF3, CL16961.Contig9_All) and Abscisic Acid Responsive Elements-binding Factor 3 (ABF3, CL9171.Contig5_All) were negatively regulated in response to 6-BA treatment. Additionally, the expression of several unigenes that involved in the regulation of hormonal signaling of ethylene (CL1635.Contig5_All, CL8680.Contig2_All, CL15911.Contig2_All and CL2328.Contig15_All), gibberellin (CL3574.Contig42_All, CL13937.Contig2_All and CL13937.Contig3_All) and jasmonic acid (CL2992.Contig3_All, CL1493.Contig4_All and CL1493.Contig2_All) was also altered in response to 6-BA treatment (Fig. 7). These results suggested that cytokinin might regulate the floral development via interactions with the other phytohormones in S. sebiferum.

\section{Identification of the differentially expressed genes related to the floral development}

The floral organ identity genes that were differentially regulated after 6-BA treatment could directly contribute to the altered sex differentiation in S. sebiferum. The transcriptome data showed that a total of 21 unigenes that closely related to flowering were found to be 


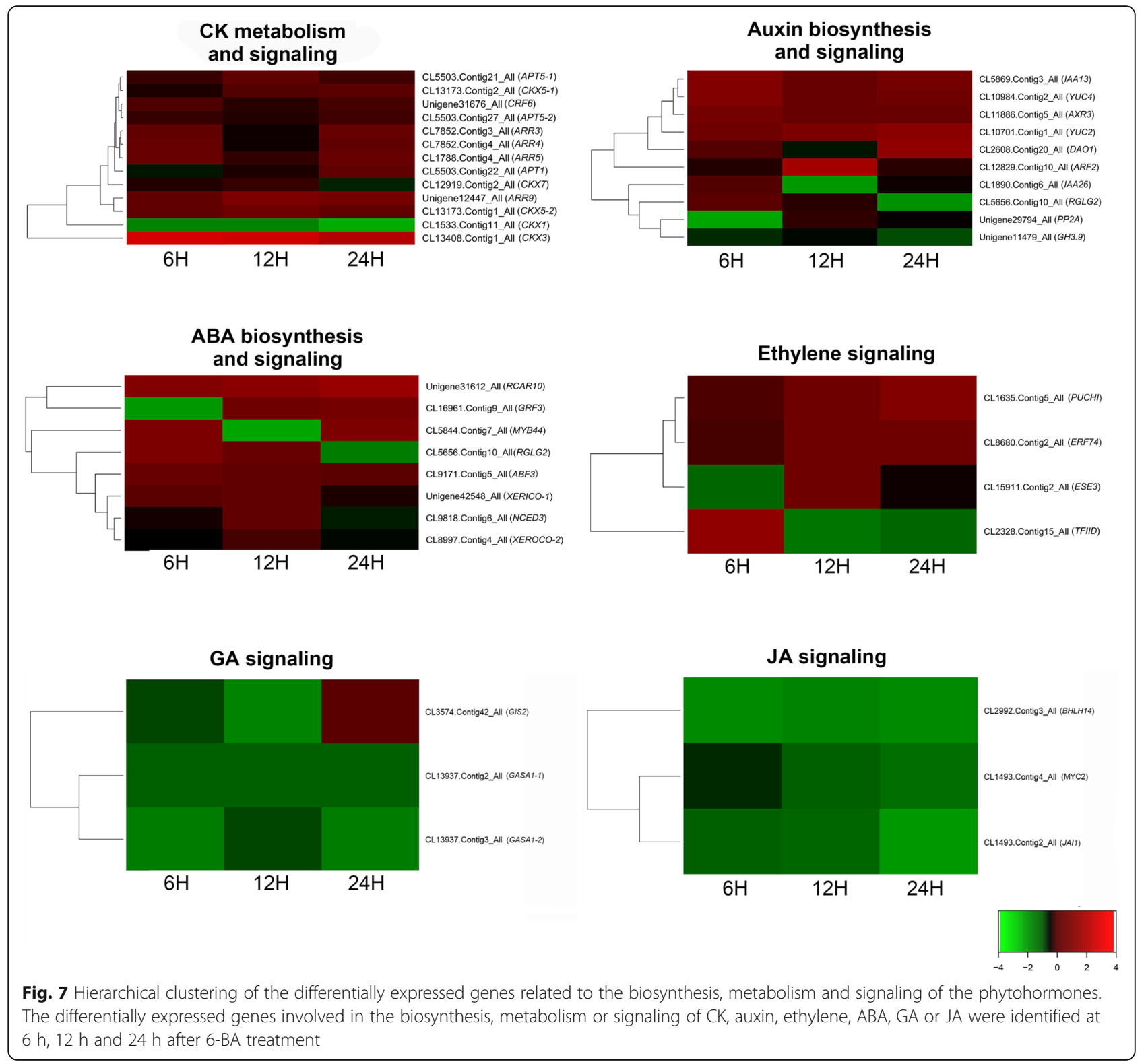

differentially expressed in response to 6-BA treatment (Fig. 8). Five genes that related to the early floral meristem development, such as PUCHI (CL1635.Contig5_All), Target of Early Activation Tagged 1 (TOE1, CL1615.Contig68_All and CL46.Contig48_All), Ethylene Response DNA Binding Factor 4 (EDF4, CL4670.Contig3_All) and WIGGUM (WIG, CL3863.Contig4_All), were differentially regulated by 6-BA treatment (Fig. 8). Further, several key genes that directly regulated the gynoecium development, such as SPATULA (SPT, Unigene42678_All), KANADI2 (KAN2, CL1205.Contig3_All), JAGGED (JAG, CL11939.Contig4_All), Cytochrome P450 78A9 (CYP78A9, CL15451.Contig2_All), and APETALA2 (AP2, CL8973.Contig2_All) were differentially regulated at $6 \mathrm{~h}, 12 \mathrm{~h}$ or $24 \mathrm{~h}$ after
6-BA treatment (Fig. 8). Moreover, a series of unigenes such as MYB Domain Protein 108 (MYB108, CL847.Contig2_All), Cadmium Induced (CDI, CL12892.Contig3_All), NPK1-Activating Kinesin 1 (NACK1, CL2667.Contig7_All), Shaker Pollen Inward K + Channel (SPIK, CL3798.Contig10_All), Vacuolar Protein Sorting 34 (VPS34, Unigene6428_All), TATA Box Associated Factor II 59 (TAFII59, CL361.Contig25_All), FERONIA (FER, CL6663.Contig3-All), Embryo Defective 1674 (EMB1674, Unigene33664_All), PISTILLATA (PI, CL12404.Contig2_All), which were related to the development of the male organs, were also differentially expressed after 6-BA treatment (Fig. 8). Conclusively, the identification and characterization of the cytokinin-responsive DEGs related to the floral organ 

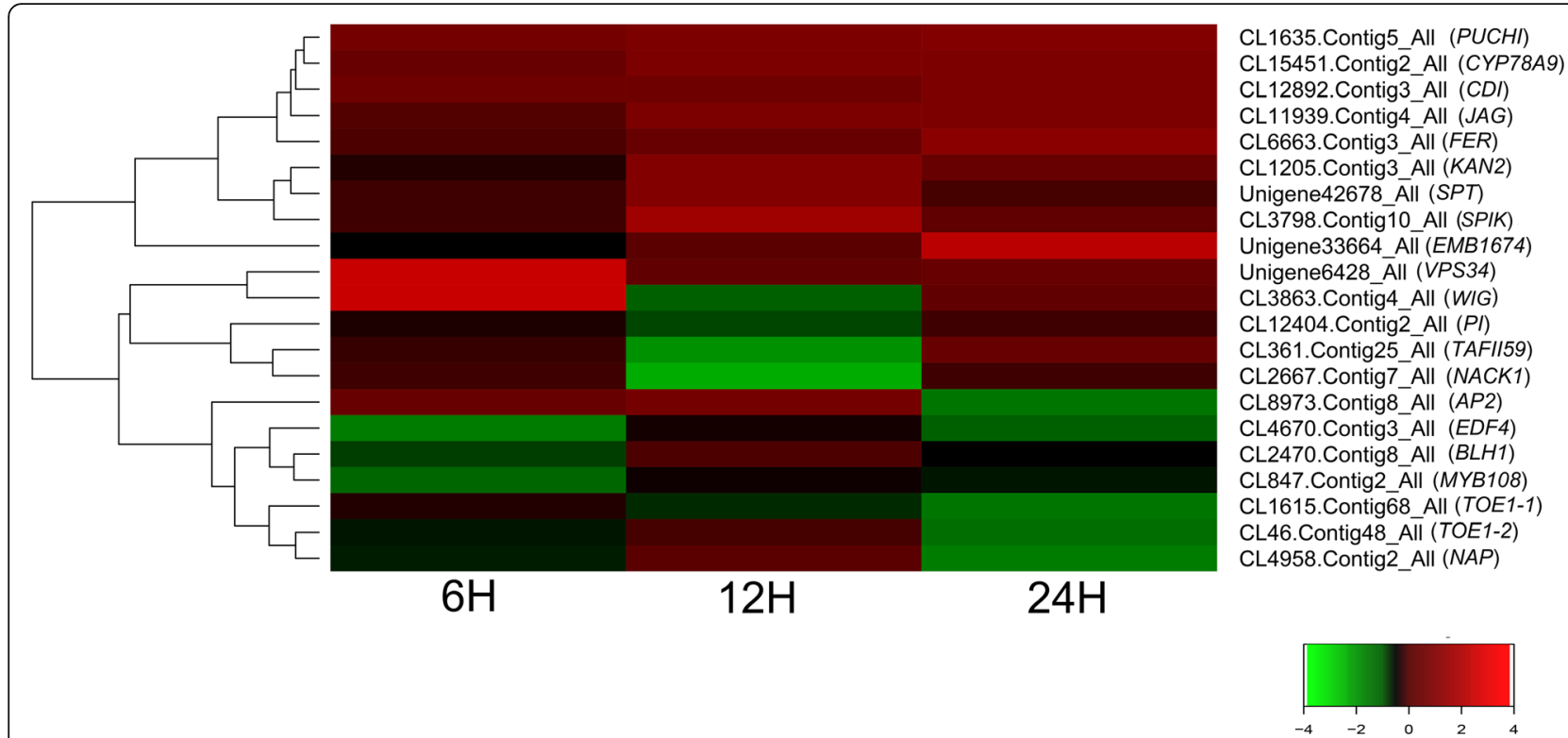

Fig. 8 Hierarchical clustering of the differentially expressed genes involved in the regulation of floral development and floral organ identity at $6 \mathrm{~h}, 12 \mathrm{~h}$ and $24 \mathrm{~h}$ after 6-BA treatment in S. sebiferum

identities provided insights in understanding the sex determination in S. sebiferum.

\section{Discussion}

\section{Cytokinin has strong feminization effects on the flower} development in both monoecious and androecious genotypes of $S$. sebiferum

The regulation of the female to male flower ratio is critical for improvement of the seed yield in the monoecious plants. Various phytohormones were demonstrated to be important regulators not only in vegetative growth, but also in the flower initiation and sex differentiation. In plants, phytohormones such as ethylene [29], gibberellins [30] and auxins [5, 31], have feminization effects in various species. Cytokinins are essential for numerous decisions throughout the plant developmental processes and adaptation to the biotic and abiotic environment [32]. In Jatropha curcas, Plukenetia volubilis and Luffa cylindrica, exogenous CK treatment can increase the number of female flowers $[9,10,33]$. Our present study in S. sebiferum were consistent with these findings that 6-BA or TDZ treatment has strong feminization effects on the floral development (Fig. 1). Although tZ and kinetin were two other types of cytokinins that can induce the division of plant cells [34], exogenous application with $\mathrm{tZ}$ and kinetin had no effects on the floral development in S. sebiferum (Fig. 1f). We postulated that in $S$. sebiferum, the regulation of floral sex might be controlled by specific cytokinin types.

Our results further demonstrated that 6-BA or TDZ application can also effectively induce the female flowers on the androecious S. sebiferum (Fig. 3). These findings suggested that cytokinin was not only the key regulator in controlling the female flower development, but also possibly was the potential determinant that involved in the formation of the androecious plants in S. sebiferum. The transcriptome sequencing of the male floral buds subjected to 6-BA treatment was carried out and abundant cytokinin-responsive genes that were possibly involved in female flower induction were further identified. The floral buds of the androecious $S$. sebiferum seemed to be less sensitive to 6-BA treatment in the transcriptomic level, since the number of the differentially expressed genes in response to 6-BA treatment (especially at $6 \mathrm{~h}$ ) was fewer (Fig. 4), compared with the transcriptome results from the other plant species [7, 35-37]. We postulated that the formation of the androecious plants in S. sebiferum was possibly due to the genetic mutations that caused the less-sensitivity to cytokinins. Nevertheless, exogenous 6-BA treatment can still effectively induce the female flower development on the androcious S. sebiferum (Fig. 3). Transcriptome analysis of the transition of the inflorescences from androecious to monoecious on the androecious plants will provide valuable information of the regulative gene network of the cytokinin-regulated sex differentiation in $S$. sebiferum.

\section{Cytokinin regulated the cell cycle and nutrient translocation}

The originally identified function of cytokinin was to promote the cell division [38]. In this study, ten cell 
cycle-related genes were identified in response to 6-BA treatment in the transcriptome database (Fig. 6a). Three D-type CYCD6 (CL3342.Contig16_All and CL3342.Contig11_All), CYCD3 (CL6841.Contig3_All) and one H-type CYCH1 (CL384.Contig6_All) cyclin genes that played important roles in the regulation of cell division [39], were up-regulated by 6-BA treatment (Fig. 6a). E2F Transcription Factor 3 (E2F3) was a key component in the cyclin D/retinoblastoma/E2F pathway, was also up-regulated at $24 \mathrm{~h}$ after 6-BA treatment [40]. Origin of Replication Complex 1B (ORC1B) that regulates the initiation of DNA replication [41], was up-regulated at $24 \mathrm{~h}$ after 6-BA treatment (Fig. 6a). NEDD1 encoding a WD40 repeat protein that plays a critical role in the cell mitosis in interactions with tubulin complex [42], was significantly up-regulated by 6-BA treatment (Fig. 6a). Two other transcription factors Block of Cell Proliferation 1 (BOP1) and NAC Domain Containing Protein 68 (NAC068) that involved in the cell cycle regulation [43, 44], were also up-regulated in response to 6-BA (Fig. 6a). Additionally, several genes encoding the DNA/RNA polymerases, such as Nuclear RNA Polymerase C1 (NRPC1, CL2915.Contig1_All), Poly(ADP-Ribose) Polymerase 1 (PARP1, CL8049.Contig5_All), NRPB4 (CL4312.Contig3_All) and Poly(A) Polymerase 2 (PAPS2, CL14256.Contig6_All), were also up-regulated by 6-BA treatment (Fig. 6a). These results suggested that exogenous application with cytokinin could cause immediate cell replication and organ enlargement via regulating the cell-cycle related genes in the floral buds in S. sebiferum.

Further, a few genes that involved in the translocation of the nutrients, such as sugar, peptide, magnesium, ammonium, nucleotide, calcium, zinc and phosphate, were also differentially expressed in response to 6-BA treatment (Fig. 6b). The altered nutrients transportation to the floral bud after 6-BA treatment could be associated with the vigorous female flower induction in the floral bud. It has been demonstrated that sugars, such as sucrose, glucose and trehalose-6-phosphate were the initiation signals involved in the flower initiation in Arabidopsis [23]. Trehalose-6-Phosphate Synthases (TPS) were the key enzymes involved in trehalose-6-phosphate biosynthesis. The homologs of TPS1 in S. sebiferum were up-regulated, whereas TPS9 and TPS10 were down-regulated in response to 6-BA treatment (Fig. 6b). Several genes such as Early Response to Dehydration 6 (ERD6), Glucose-6-Phosphate Translocator 2 (GPT2), Nucleotide/Sugar Transporter (NST) that involved in the sugar translocation [45-47], were also differentially regulated by 6 -BA treatment (Fig. 6b). These results suggested that the cytokinin-responsive cell cycle and cell metabolism-related genes could be involved in the regulation of flowering.
Cytokinin regulated the biosynthesis, transportation and signaling of other phytohormones in the regulation of sex determination in S. sebiferum

Phytohormones, such as auxin, cytokinin (CK), abscisic acid (ABA), ethylene (ETH), brassinosteroid (BR), gibberellin (GA), jasmonic acid (JA) and salicylic acid (SA), coordinate plant growth and development by modulating various cellular changes in response to the environmental or intrinsic signals [4]. The transcriptome data showed that many genes that were directly related to the biosynthesis, transportation and signaling of other phytohormones, were differentially regulated by 6-BA treatment in the floral buds of the androecious S. sebiferum. Specifically, ten genes were identified in auxin biosynthesis and signaling, eight genes in ABA biosynthesis and signaling, four genes in ethylene signaling, three gene in GA signaling, and three genes in JA signaling (Fig. 7). Previous studies demonstrated that cytokinin and auxin mutually regulated their biosynthesis and signaling in the regulation of plant growth and development [48]. Exogenous application with cytokinin in young shoot up-regulated the expression of auxin biosynthesis genes, such as YUCCA (YUC) [49]. In this study, two YUC genes YUC2 and YUC4 were found to be significantly up-regulated at $6 \mathrm{~h}, 12 \mathrm{~h}$ and $24 \mathrm{~h}$ in response to 6-BA treatment (Fig. 7). Ring Domain Ligase 2 (RGLG2) was previously reported to be involved in the regulation of auxin metabolism. Mutation of RGLG2 could cause significant decrease of auxin content in both leaf and root in Arabidopsis [50]. The expression of RGLG2 was increased in response to 6-BA treatment in S. sebiferum (Fig. 7). The results also showed that the expression of Dioxygenase for Auxin Oxidation 1 (DAO1), which encoded a major IAA oxidase in plants [28], was found to be down-regulated at $12 \mathrm{~h}$, whereas promoted at $24 \mathrm{~h}$ (Fig. 7). These results suggested that the auxin biosynthesis was transiently promoted, at least in a short time after 6-BA treatment at the floral buds. Additionally, several auxin signaling and transportation-related genes, such as Auxin Response Factor 2 (ARF2), Indole-3-Acetic Acid Inducible 13 (IAA13), Indole-3-Acetic Acid Inducible 26 (IAA26), GH3.9, Auxin Resistant 3 (AXR3) and Protein Phosphatase 2A (PP2A) were found to be mostly up-regulated in response to 6-BA treatment (Fig. 7). It has been demonstrated that auxin was important for the female reproductive organ development in Arabidopsis [51], and also exhibited a strong feminization effect on Cannabis sativus and Opuntia stenopetala [5, 31]. The expression of auxin signaling genes was also positively correlated with the transition to female flowers on the monoecious Ricinus communis [52]. Our results were in accord with these findings that auxin could also play important role in the female flower induction regulated by cytokinin in S. sebiferum. 
In cucumber, $\mathrm{ABA}$ did not change the sex expression, nevertheless it promoted the female tendency of gynoecious plants [53]. XERICO and Nine-cis-epoxycarotenoid Dioxygenase 3 (NCED3) are two important regulators in ABA biosynthesis [54, 55]. The transcriptome data showed that these two genes were significantly down-regulated by 6-BA treatment (Fig. 7). The ABA signaling-related genes, such as Ring Domain Ligase 2 (RGLG2), ATMYB44 (MYB44), Growth Regulating Factor 3 (GRF3) and Abscisic Acid Responsive Elements-binding Factor 3 (ABF3) were down-regulated by 6-BA treatment (Fig. 7). Previous studies showed that ABA and cytokinin antagonistically regulated many aspects of plant growth and development [56, 57]. In S. sebiferum, the cytokinin responsiveness of the ABA biosynthesis and signaling-related genes suggested an antagonistic interactions between $\mathrm{CK}$ and $\mathrm{ABA}$ in the regulation of the floral development.

Cytokinin also interacted with ETH, GA and JA in the regulation of flowering [58]. PUCHI, a key component in ethylene-activated signaling pathway, was required for morphogenesis in the early floral meristem growth [59]. The transcript abundance of $P U C H I$ in the floral bud was up-regulated in response to 6-BA treatment (Fig. 7). The S. sebiferum orthologs of three additional ethylene signaling-related genes, Ethylene Response Factor 74 (ERF74), Ethylene and Salt Inducible 3 (ESE3) and Transcription Factor IID (TFIID) were also differentially regulated by 6-BA treatment (Fig. 7), suggesting a potential interactions between CK and ETH in the regulation of sex determination in S. sebiferum. Among these differentially expressed genes after 6-BA treatment, three JA signaling genes ATMYC2 (MYC2), Jasmonate Insensitive 1
(JAI1), BHLH14 and three GA signaling genes GA-Stimulated Arabidopsis 1 (GASA1-1 and GASA1-2) and Glabrous Inflorescence Stems 2 (GIS2) were differentially regulated in response to 6-BA treatment (Fig. 7). Conclusively, these results implied that cytokinin interacted with auxin, ABA, ethylene, JA and GA in sex determination in S. sebiferum (Fig. 9).

\section{Cytokinin regulated the expression of gynoecium and androecium identity-related genes}

6-BA treatment profoundly induced the formation of female flowers in the androecious S. sebiferum (Fig. 3). The differential expression of ABCE floral organ-identity genes has been implicated in the regulation of male and female flower development $[60,61]$. Thus it suggested that cytokinin could directly target the floral organ-identity genes in the regulation of sex determination. A total of 21 flowering-related genes were identified in response to 6-BA treatment at the floral bud of the androecious plants (Fig. 8). Several early floral meristem growth-related genes, such as PUCHI, Target of Early Activation Tagged 1 (TOE1), Ethylene Response DNA Binding Factor 4 (EDF4) and WIGGUM (WIG), were differentially regulated in response to 6-BA treatment (Fig. 8), suggesting cytokinin was directly involved in the regulation of the early floral meristem development in S. sebiferum. Among the DEGs, a few genes that were closely related to the gynoecium and androecium development, were found to be differentially regulated in response to 6-BA treatment. SPATULA (SPT), a bHLH transcription factor, was involved in gynoecium development [62], was up-regulated at $12 \mathrm{~h}$ after 6-BA treatment (Fig. 8). KANADI 2 (KAN2), which encodes a

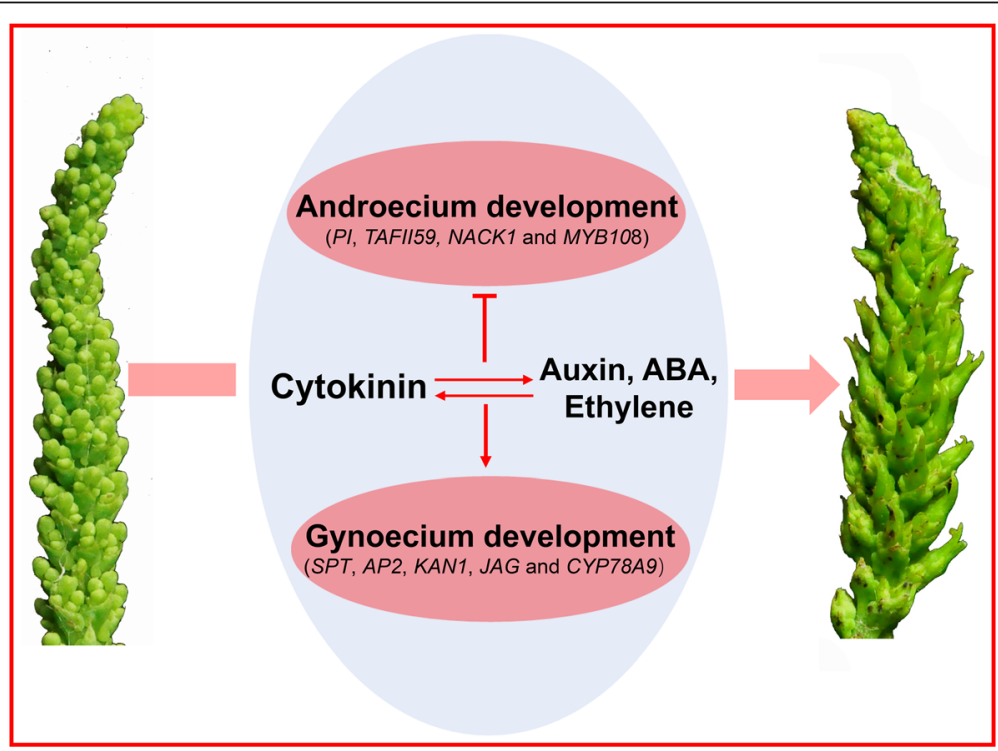

Fig. 9 Role of cytokinins in the regulation of sex determination in S. sebiferum 
nuclear-localized protein involved in the development of the carpel and the outer integument of the ovule [63], was also up-regulated at $12 \mathrm{~h}$ (Fig. 8). The transcript abundance of two other genes JAGGED (JAG) and Cytochrome P450 $78 A 9$ (CYP79A9), which were positively related to gynoecium development $[64,65]$, were up-regulated at 12 and $24 \mathrm{~h}$ (Fig. 8). APETALA 2 (AP2), a member of the $A P 2 / E R E B P$ class of transcription factors, was involved in the specification of floral organ identity. In Arabidopsis, mutation of AP2 would cause the transition of perianth organs to carpels [66]. The transcriptome results showed that the expression of $A P 2$ in S. sebiferum was significantly decreased at $24 \mathrm{~h}$ after 6-BA treatment (Fig. 8), suggesting a feminization effect of cytokinin on the floral sex in S. sebiferum. Additionally, several genes, such as MYB Domain Protein 108 (MYB108), NPK1-Activating Kinesin 1 (NACK1), TATA Box Associated Factor II 59 (TAFII59) that were important in the regulation of androecium development [67-69], were down-regulated in response to 6-BA treatment (Fig. 8). PISTILLATA (PI) which encodes a MADS domain transcription factor in regulating the specification of the petal and stamen identities [70], was also down-regulated by 6-BA treatment (Fig. 8), suggesting cytokinin had inhibitory effects on the androecium development in S. sebiferum. These results demonstrated that cytokinin regulated the sex differentiation in S. sebiferum by directly targeting the genes related to the gynoecium and androecium development (Fig. 9).

\section{Conclusions}

Conclusively, this study revealed that exogenous application with cytokinin has strong feminization effects on the floral development in S. sebiferum. The transcriptome analysis of the transition from the androecious to monoecious inflorescences after 6-BA treatment on the androecious S. sebiferum contributed to the identification of the candidate genes that were involved in the regulation of sex determination in response to cytokinin. Our study provided a basis for further understanding the molecular mechanisms of the hormonal regulation of sex determination in S. sebiferum.

\section{Additional files}

Additional file 1: Figure S1. Photographs of the floral buds used for hormonal treatment and RNA-sequencing. (TIF 5697 kb)

Additional file 2: Table S1. Primers for quantitative real-time PCR (DOCX $16 \mathrm{~kb}$ )

Additional file 3: Figure S2. Photograph of the inflorescences of different genotypes of S. sebiferum. (TIF $1797 \mathrm{~kb}$ )

Additional file 4: Tables S2-S4. Information of the assembled genes at $6 \mathrm{~h}, 12 \mathrm{~h}$ and $24 \mathrm{~h}$. (XLSX $48555 \mathrm{~kb})$
Additional file 5: Tables S5-S7. Differentially expressed genes at $6 \mathrm{~h}$, $12 \mathrm{~h}$ and $24 \mathrm{~h}$ after 6-BA treatment. (XLSX $363 \mathrm{~kb}$ )

Additional file 6: Figure S3. $\mathrm{GO}$ analysis of the differentially expressed genes at $6 \mathrm{~h}(\mathrm{~A}), 12 \mathrm{~h}$ (B) and $24 \mathrm{~h}$ (C) after 6-BA and mock treatment. (TIF $1842 \mathrm{~kb})$

\section{Abbreviations}

ABA: Abscisic acid; BA: Benzylaminopurine; DEG: Differentially expressed genes; ETH: Ethylene; GA: Gibberellin; GO: Gene ontology; JA: Jasmonic acid; KEGG: Kyoto Encyclopedia of Genes and Genomes; PCR: Polymerase chain reaction; qPCR: Quantitative real time polymerase chain reaction; RNAseq: RNA sequencing; RPKM: Reads per kilobase per million mapped reads; TDZ: Thidiazuron; TF: Transcription factor

\section{Acknowledgements}

The authors are grateful to Mr. Li for the assistance of the field work. We also thank Dr. Kaiqin Ye for the suggestions for the manuscript.

\section{Funding}

This work was funded by National Natural Science Foundation of China (31500531), the Science and Technology Service program of Chinese Academy of Sciences (KFJ-STS-ZDTP-002), the key program of 13th five-year plan, CASHIPS (No. kp-2017-21), the Grant of the President Foundation of Hefei Institutes of Physical Science of Chinese Academy of Sciences (YZJJ201619), the major special project of Anhui Province (16030701103) and Natural Science Foundation of Anhui province (1708085QC70).

\section{Availability of data and materials}

All the data in the study has been included in the tables and figures in this manuscript. RNA-seq data of this project have been deposited in Genbank under the SRA accession number PRJNA438002.

\section{Authors' contributions}

JN and LW designed the experiments. JN, FAS, WL, QW, DW, WZ and WL carried out the experiments. JN, FAS, SH and SF analyzed and interpreted the transcriptome sequencing data. JN wrote the manuscript. All authors read and approved the final manuscript.

Ethics approval and consent to participate

Not applicable.

Competing interests

The authors declare that they have no competing interests.

\section{Publisher's Note}

Springer Nature remains neutral with regard to jurisdictional claims in published maps and institutional affiliations.

\section{Author details}

${ }^{1}$ Key laboratory of high magnetic field and lon beam physical biology, Hefei Institutes of Physical Science, Chinese Academy of Sciences, Hefei, Anhui 230031, China. ${ }^{2}$ School of Forestry and Landscape Architecture, Anhui Agricultural University, Hefei, Anhui, China.

Received: 6 April 2018 Accepted: 18 May 2018

Published online: 30 May 2018

References

1. Xu I, Chikashige T, Meguro S, Kawachi S. Effective utilization of Stillingia or Chinese tallow tree (Sapium sebiferum) fruits. Mokuzai Gakkaishi. 1991;37(5):494-8.

2. Peng D, Zhang L, Tan XF, Yuan DY, Liu XM, Zhou B. Increasing seed oil content and altering oil quality of Brassica napus $L$. by over-expression of diacylglycerol acyltransferase 1 (SsDGAT1) from Sapium sebiferum (L.) Roxb. Mol Breeding. 2016;36(10):136.

3. Gao Y, Chen W, Lei H, Liu Y, Lin X, Ruan R. Optimization of transesterification conditions for the production of fatty acid methyl ester (FAME) from Chinese tallow kernel oil with surfactant-coated lipase. Biomass Bioenergy. 2009;33(2):277-82. 
4. Golenberg EM, West NW. Hormonal interactions and gene regulation can link monoecy and environmental plasticity to the evolution of dioecy in plants. Am J Bot. 2013;100(6):1022-37.

5. Orozco-Arroyo G, Vazquez-Santana S, Camacho A, Dubrovsky JG, Cruz-Garcia F. Inception of maleness: auxin contribution to flower masculinization in the dioecious cactus Opuntia stenopetala. Planta. 2012;236(1):225-38.

6. Chen MS, Pan BZ, Fu Q, Tao YB, Martínezherrera J, Niu L, Ni J, Dong Y, Zhao $\mathrm{ML}, \mathrm{Xu}$ ZF. Comparative transcriptome analysis between gynoecious and monoecious plants identifies regulatory networks controlling sex determination in Jatropha curcas. Front Plant Sci. 1953;7:2016.

7. Pan BZ, Chen MS, Ni J, Xu ZF. Transcriptome of the inflorescence meristems of the biofuel plant Jatropha curcas treated with cytokinin. BMC Genomics. 2014;15(1):974

8. Yin TJ, Quinn JA. Tests of a mechanistic model of one hormone regulating both sexes in Cucumis sativus (Cucurbitaceae). Am J Bot. 1995;82(12):1537-46.

9. Pan BZ, Xu ZF. Benzyladenine treatment significantly increases the seed yield of the biofuel plant Jatropha curcas. J Plant Growth Regul. 2011; 30(2):166-74.

10. Fu QT, Niu L, Zhang QF, Pan BZ, He HY, Xu ZF. Benzyladenine treatment promotes floral feminization and fruiting in a promising oilseed crop Plukenetia volubilis. Ind Crop Prod. 2014;59(x):295-8.

11. Ni J, Gao C, Chen M-S, Pan B-Z, Ye K, Xu Z-F. Gibberellin promotes shoot branching in the perennial woody plant Jatropha curcas. Plant Cell Physiol. 2015;56(8):1655-66.

12. Zhang M, Sun H, Fei Z, Zhan F, Gong X, Gao S. Fastq_clean: An optimized pipeline to clean the Illumina sequencing data with quality control. In: IEEE International Conference on Bioinformatics and Biomedicine; 2014. p. 44-8.

13. Andrews $\mathrm{S}$ : FastQC a quality control tool for high throughput sequence data. 2010.

14. Haas BJ, Papanicolaou A, Yassour M, Grabherr M, Blood PD, Bowden J, Couger MB, Eccles D, Li B, Lieber M. De novo transcript sequence reconstruction from $\mathrm{RNA}$-seq using the trinity platform for reference generation and analysis. Nature Protocol. 2013;8(8):1494-512.

15. Langmead B, Trapnell C, Pop M, Salzberg SL. Ultrafast and memory-efficient alignment of short DNA sequences to the human genome. Genome Biol. 2009;10:R25

16. Davidson NM, Oshlack A. Corset: enabling differential gene expression analysis for de novo assembled transcriptomes. Genome Biol. 2014;15:410.

17. Conesa A, Gotz S, Garcia-Gomez JM, Terol J, Talon M, Robles M. Blast2GO: a universal tool for annotation, visualization and analysis in functional genomics research. Bioinformatics. 2005;21(18):3674-6.

18. Ye J, Fang L, Zheng H, Zhang Y, Chen J, Zhang Z, Wang J, Li S, Li R, Bolund L, et al. WEGO: a web tool for plotting GO annotations. Nucleic Acids Res. 2006:34:293-7.

19. Kanehisa M, Goto S, Sato Y, Furumichi M, Tanabe M. KEGG for integration and interpretation of large-scale molecular data sets. Nucleic Acids Res. 2012;40(1):109-14.

20. Tatusov RL, Natale DA, Garkavtsev IV, Tatusova TA, Shankavaram UT, Rao BS, Kiryutin B, Galperin MY, Fedorova ND, Koonin EV. The COG database: new developments in phylogenetic classification of proteins from complete genomes. Nucleic Acids Res. 2001;29(1):22-8.

21. Trapnell C, Williams BA, Pertea G, Mortazavi A, Kwan G, van Baren MJ, Salzberg SL, Wold BJ, Pachter L. Transcript assembly and quantification by RNA-Seq reveals unannotated transcripts and isoform switching during cell differentiation. Nature Biotechnol. 2010;28(5):511-174.

22. Gao R, Su Z, Yin Y, Sun L, Li S. Germplasm, chemical constituents, biological activities, utilization, and control of Chinese tallow ( Triadica sebifera (L.) small). Biol Invas. 2016;18(3):1-21.

23. Wahl V, Ponnu J, Schlereth A, Arrivault S, Langenecker T, Franke A, Feil R, Lunn JE, Stitt M, Schmid M. Regulation of flowering by trehalose-6phosphate signaling in Arabidopsis thaliana. Science. 2013;339(6120):704-7.

24. Allen M, Qin WS, Moreau F, Moffatt B. Adenine phosphoribosyltransferase isoforms of Arabidopsis and their potential contributions to adenine and cytokinin metabolism. Physiol Plant. 2002;115(1):56-68.

25. Smehilova M, Dobruskova J, Novak O, Takac T, Galuszka P. Cytokinin-specific glycosyltransferases possess different roles in cytokinin homeostasis maintenance. Front Plant Sci. 2016;7:1264

26. To JP, Haberer G, Ferreira FJ, Deruere J, Mason MG, Schaller GE, Alonso JM, Ecker JR, Kieber JJ. Type-a Arabidopsis response regulators are partially redundant negative regulators of cytokinin signaling. Plant Cell. 2004;16(3):658-71.
27. Cheng $Y$, Dai $X$, Zhao $Y$. Auxin synthesized by the YUCCA flavin monooxygenases is essential for embryogenesis and leaf formation in Arabidopsis. Plant Cell. 2007;19(8):2430-9.

28. Zhang J, Lin JE, Harris C, Campos Mastrotti Pereira F, Wu F, Blakeslee JJ, Peer WA. DAO1 catalyzes temporal and tissue-specific oxidative inactivation of auxin in Arabidopsis thaliana. Proc Natl Acad Sci. 2016;113(39):11010-5.

29. Ando S, Sato Y, Kamachi S, Sakai S. Isolation of a MADS-box gene (ERAF17) and correlation of its expression with the induction of formation of female flowers by ethylene in cucumber plants (Cucumis sativus L.). Planta. 2001; 213(6):943-52.

30. Dellaporta SL, Calderonurrea A. The sex determination process in maize. Science. 1994;266(5190):1501-5.

31. Heslop-Harrison J. Auxin and Sexuality in Cannabis sativa. Physiol Plant. 2010;9(4):588-97.

32. Zuercher $\mathrm{E}$, Mueller B. Cytokinin synthesis, signaling, and function-advances and new insights. Int Rev Cell Mol Biol. 2016;324:1-38.

33. Takahashi $H$, Suge H, Saito T. Sex expression as affected by N 6benzylaminopurine in staminate inflorescence of Luffa cylindrica. Plant Cell Physiol. 1980;21(4):525-36.

34. Cohen I, Raz S, Malah D. Kinetin-a multiactive molecule. Int J Biol Macromol 2007:40(3):182-92

35. Fu Q, Niu L, Chen MS, Tao YB, Wang X, He H, Pan BZ, Xu ZF. De novo transcriptome assembly and comparative analysis between male and benzyladenine-induced female inflorescence buds of Plukenetia volubilis. J Plant Physiol. 2018;221:107-18.

36. Chen MS, Pan BZ, Wang GJ, Ni J, Niu L, Xu ZF. Analysis of the transcriptional responses in inflorescence buds of Jatropha curcas exposed to cytokinin treatment. BMC Plant Biol. 2014;14(1):318.

37. Raines T, Blakley IC, Tsai Y-C, Worthen JM, Franco-Zorrilla JM, Solano R, Schaller GE, Loraine AE, Kieber JJ. Characterization of the cytokininresponsive transcriptome in rice. BMC Plant Biol. 2016;16(1):260

38. Skoog FMC. Chemical regularion of growth and organ formation in plant fissue cultured. Symp Soc Exp Biol. 1957;11:118-31.

39. Rioukhamlichi C, Huntley R, Jacamard A, Murray JA. Cytokinin activation of Arabidopsis cell division through a D-type cyclin. Science. 1999; 283(5407):1541-4

40. Kosugi S, Ohashi Y. Constitutive E2F expression in tobacco plants exhibits altered cell cycle control and morphological change in a cell type-specific manner. Plant Physiol. 2003;132(4):2012-22.

41. Paz Sanchez MDL, Gutierrez C. Arabidopsis ORC1 is a PHD-containing H3K4me3 effector that regulates transcription. Proc Natl Acad Sci U S A. 2009;106(6):2065-70.

42. Zeng CJT, Lee YRJ, Liu B. The WD40 repeat protein NEDD1 functions in microtubule organization during cell division in Arabidopsis thaliana. Plant Cell. 2009;21(4):1129-40.

43. Ahn CS, Cho HK, Lee DH, Sim HJ, Kim SG, Pai HS. Functional characterization of the ribosome biogenesis factors PES, BOP1, and WDR12 (PeBOW), and mechanisms of defective cell growth and proliferation caused by PeBoW deficiency in Arabidopsis. J Exp Bot. 2016:67(17):5217-32.

44. Kim YS, Kim SG, Park JE, Park HY, Lim MH, Chua NH, Park CM. A membranebound NAC transcription factor regulates cell division in Arabidopsis. Plant Cell. 2006;18(11):3132-44.

45. Kiyosue T, Abe H, Yamaquchi-Shinozaki K, Shinozaki K. ERD6, a cDNA clone for an early dehydration-induced gene of Arabidopsis, encodes a putative sugar transporter. Bioch Biophysica Act. 1998;1370(2):187-91.

46. Dyson BC, Allwood JW, Feil R, Yun XU, Miller M, Bowsher CG, Goodacre R, Lunn JE, Johnson GN. Acclimation of metabolism to light in Arabidopsis thaliana: the glucose 6-phosphate/phosphate translocator GPT2 directs metabolic acclimation. Plant Cell Environ. 2015;38(7):1404-17.

47. Handford M, Rodríguez-Furlán C, Marchant L, Segura M, Gómez D. Arabidopsis thaliana AtUTr7 encodes a golgi-localized UDP-glucose/UDPgalactose transporter that affects lateral root emergence. Mol Plant. 2012; 5(6):1263-80.

48. Nordström A, Tarkowski P, Tarkowska D, Norbaek R, Åstot C, Dolezal K, Sandberg G. Auxin regulation of cytokinin biosynthesis in Arabidopsis thaliana: a factor of potential importance for auxin-cytokinin-regulated development. Proc Natl Acad Sci U S A. 2004;101(21):8039-44.

49. Jones B, Gunnerås SA, Petersson SV, Tarkowski P, Graham N, May S, Dolezal K, Sandberg G, Ljung K. Cytokinin regulation of auxin synthesis in Arabidopsis involves a homeostatic feedback loop regulated via auxin and cytokinin signal transduction. Plant Cell. 2010;22(9):2956-69. 
50. Yin X-J, Volk S, Ljung K, Mehlmer N, Dolezal K, Ditengou F, Hanano S, Davis SJ, Schmelzer E, Sandberg G, et al. Ubiquitin lysine 63 chain-forming ligases regulate apical dominance in Arabidopsis. Plant Cell. 2007;19(6):1898-911.

51. Cucinotta M, Manrique S, Guazzotti A, Quadrelli NE, Mendes MA, Benkova E, Colombo L. Cytokinin response factors integrate auxin and cytokinin pathways for female reproductive organ development. Development. 2016; 143(23):dev.143545.

52. Tan M, Xue J, Wang L, Huang J, Fu C, Yan X. Transcriptomic analysis for different sex types of Ricinus communis $\mathrm{L}$. during development from apical buds to inflorescences by digital gene expression profiling. Front Plant Sci. 2016;6:1208.

53. Rudich J, Halevy AH. Involvement of abscisic acid in the regulation of sex expression in the cucumber. Plant Cell Physiol. 1974;15(4):635-42.

54. Ko JH, Yang SH, Han KH. Upregulation of an Arabidopsis RING-H2 gene, XERICO, confers drought tolerance through increased abscisic acid biosynthesis. Plant J. 2006;47(3):343-55.

55. Sussmilch FC, Brodribb TJ, Sam MA. Up-regulation of NCED3 and ABA biosynthesis occur within minutes of a decrease in leaf turgor but $A H K 1$ is not required. J Exp Bot. 2017;68(11):2913-8.

56. Cowan AK, Cairns ALP, Bartelsrahm B. Regulation of abscisic acid metabolism: towards a metabolic basis for abscisic acid-cytokinin antagonism. J Exp Bot. 1999:50(334):595-603.

57. Cowan AK, Railton ID. Cytokinins and ancymidol inhibit abscisic acid biosynthesis in Persea gratissima. J Plant Physiol. 1987;130(2-3):273-7.

58. Elshowk S, Ruonala R, Helariutta Y. Crossing paths: cytokinin signalling and crosstalk. Development. 2013;140(7):1373-83.

59. Chandler JW, Werr W. DORNRÖSCHEN, DORNRÖSCHEN-LIKE, and PUCHI redundantly control floral meristem identity and organ initiation in Arabidopsis. J Exp Bot. 2017;68(13):3457-72.

60. Pfent C, Pobursky K, Sather DN, Golenberg E. Characterization of SpAPETALA3 and SpPISTILLATA, B class floral identity genes in Spinacia oleracea, and their relationship to sexual dimorphism. Dev Gen Evolut. 2005; 215(3):132-42.

61. Li S-F, Zhang G-J, Zhang X-J, Yuan J-H, Deng C-L, Gao W-J. Comparative transcriptome analysis reveals differentially expressed genes associated with sex expression in garden asparagus (Asparagus officinalis). BMC Plant Biol. 2017;17(1):143.

62. Schuster C, Gaillochet C, Lohmann JU. Arabidopsis HECATE genes function in phytohormone control during gynoecium development. Development. 2015;142(19):3343-50.

63. Pires HR, Monfared MM, Shemyakina EA, Fletcher JC. ULTRAPETALA trxG genes interact with KANADI transcription factor genes to regulate Arabidopsis gynoecium patterning. Plant Cell. 2014;26(11):4345-61

64. Dinneny JR, Yadegari R, Fischer RL, Yanofsky MF, Weigel D. The role of JAGGED in shaping lateral organs. Development. 2004;131(5):1101-10.

65. Sotelosilveira M, Cucinotta M, Chauvin AL, Colombo L, De FS. Cytochrome P450 CYP78A9 is involved in Arabidopsis reproductive development. Plant Physiol. 2013;162(2):779-99.

66. Kunst L, Klenz JE, Martinez-Zapater J, Haughn GW. AP2 gene determines the identity of perianth organs in flowers of Arabidopsis thaliana. Plant Cell. 1989;1 (12):1195-208.

67. Mandaokar A, Browse J. MYB108 acts together with MYB24 to regulate jasmonate-mediated stamen maturation in Arabidopsis. Plant Physiol. 2009; 149(2):851-62.

68. Oh SA, Bourdon V, Pal MD, Dickinson H, Twell D. Arabidopsis kinesins HINKEL and TETRASPORE act redundantly to control cell plate expansion during cytokinesis in the male gametophyte. Mol Plant. 2008;1 (5):794-9.

69. Lago C, Clerici E, Dreni L, Horlow C, Caporali E, Colombo L, Kater MM. The Arabidopsis TFIID factor AtTAF6 controls pollen tube growth. Dev Biol. 2005; 285(1):91-100.

70. Wuest SE, Wellmer F. Molecular basis for the specification of floral organs by APETALA3 and PISTILLATA. Proc Natl Acad Sci U S A. 2012;109(33):13452.

\section{Ready to submit your research? Choose BMC and benefit from:}

- fast, convenient online submission

- thorough peer review by experienced researchers in your field

- rapid publication on acceptance

- support for research data, including large and complex data types

- gold Open Access which fosters wider collaboration and increased citations

- maximum visibility for your research: over $100 \mathrm{M}$ website views per year

At BMC, research is always in progress.

Learn more biomedcentral.com/submissions 